Article

\title{
Feasibility Study on the Design and Synthesis of Functional Porous Organic Polymers with Tunable Pore Structure as Metallocene Catalyst Supports
}

\author{
Xiong Wang * (D), Cuiling Zhang, Wenxia Liu and Pingsheng Zhang \\ Lanzhou Petrochemical Research Center, Petrochemical Research Institute, PetroChina, Lanzhou 730060, China; \\ zhangcuiling3@petrochina.com.cn (C.Z.); liuwenxia1@petrochina.com.cn (W.L.); \\ zhangpingsheng@petrochina.com.cn (P.Z.) \\ * Correspondence: wangxiong1@petrochina.com.cn; Tel.: +86-931-7983474
}

Received: 29 June 2018; Accepted: 22 August 2018; Published: 24 August 2018

\begin{abstract}
Porous organic polymers (POPs) are highly versatile materials that find applications in adsorption, separation, and catalysis. Herein, a feasibility study on the design and synthesis of POP supports with a tunable pore structure and high ethylene-polymerization activity was conducted by the selection of functional comonomers and template agents, and control of cross-linking degree of their frameworks. Functionalized POPs with a tunable pore structure were designed and synthesized by a dispersion polymerization strategy. The functional comonomers incorporated in the poly(divinylbenzene) (PDVB)-based matrix played a significant role in the porous structure and particle morphology of the prepared polymers, and a specific surface area (SSA) of 10-450 $\mathrm{m}^{2} / \mathrm{g}$, pore volume (PV) of $0.05-0.5 \mathrm{~cm}^{3} / \mathrm{g}$, bulk density with a range of $0.02-0.40 \mathrm{~g} / \mathrm{cm}^{3}$ were obtained by the varied functional comonomers. Besides the important factors of thermodynamic compatibility of the selected solvent system, other factors that could be used to tune the pore structure and morphology of the POP particles have been also investigated. The $\mathrm{Fe}_{3} \mathrm{O}_{4}$ nanoaggregates as a template agent could help improve the porous structure and bulk density of the prepared POPs, and the highly cross-linking networks can dramatically increase the porous fabric of the prepared POPs. As for the immobilized metallocene catalysts, the pore structure of the prepared POPs had a significant influence on the loading amount of the $\mathrm{Zr}$ and $\mathrm{Al}$ of the active sites, and the typically highly porous structure of the POPs would contribute the immobilization of the active species. High ethylene-polymerization activity of $8033 \mathrm{~kg} \mathrm{PE} / \mathrm{mol} \mathrm{Zr} \mathrm{h}$ bar was achieved on the POPs-supported catalysts, especially when high $\mathrm{Al} / \mathrm{Zr}$ ratios on the catalysts were obtained. The performance of the immobilized metallocene catalysts was highly related to the pore structure and functional group on the POP frameworks.
\end{abstract}

Keywords: porous organic polymer (POP); metallocene catalyst; ethylene polymerization; pore structure

\section{Introduction}

Porous organic polymers (POPs) have received a staggering degree of attention in various research areas, including adsorption, separation, and heterogeneous catalysis, owing to their huge surface area, tunable pore size, flexible synthetic strategy, and readily modifiable functionality [1-9]. Numerous studies on these porous organic materials, including covalent organic frameworks (COFs) and porous coordination polymers (PCPs) or metal-organic frameworks (MOFs), as olefin polymerization-catalyst supports and mobilization procedures have been investigated [10-12]. Unlike inorganic supports, such as silica gel, zeolites, molecular sieves, which need complex chemical treatments to get rid of acidic groups on their surfaces and present residual inorganic fragments within the produced polyolefins that may affect their mechanical and optical properties [13-16], POPs offer significant advantages over 
their inorganic equivalents: they provide a much closer analogue to the environment prevailing in the homogeneous polymerization, do not require a fastidious immobilization procedure, and should not significantly affect the final polyolefin properties [17-20].

The rich variety of organic building blocks combined with the diverse polymerizations has led to various types of novel POPs [21-25], and POPs could be divided into two categories, amorphous and crystalline, according to the crystalline tendency of the molecular chains of the polymers. Generally, the pore structure and topologies of the crystalline POPs are well-defined, including crystalline covalent organic frameworks (COFs) and porous coordination polymers (PCPs) or metal-organic frameworks (MOFs) [26-28]. The absence of functional groups such as catalytic sites, however, renders them relatively nonspecific, as porous materials for applications such as heterogeneous catalysis and others, and the targeted functional groups should be incorporated in the organic frameworks in order to accommodate active sites [21]. Pre- and postsynthetic modification methods were developed to functionalize the crystalline POPs. Unfortunately, the routes and methods of preparation of immobilized olefin polymerization catalysts are usually complex and the polymerization activities are unsatisfactory compared to other industrial catalysts [29,30]. Furthermore, the incorporation of functional groups and active sites, in turn, would cause defects on the frameworks broadening the pore-size distribution of the pore structure [21,31].

Amorphous POPs including polymers of intrinsic microporosity (PIMs), highly cross-linked networks (also called microporous polymer networks, MPNs), and conjugated microporous polymers (CMPs) are formed under kinetic control and show no long-range molecular order [32-34]. Typically, they have a wide range of pore-size distribution and unspecified topologies. The synthetic strategy and the post modifications of this kind of POPs, however, are pretty flexible due to diverse synthetic methods and suitable functional monomers to incorporate the active species of olefin polymerization. The produced olefin catalysts immobilized on this kind of POPs are typically highly active in terms of olefin (co)polymerization. In our previous work [35-37], we have reported that the pore size and pore-size distribution of the produced HEMA-functionalized POPs are highly tunable by a dispersion polymerization strategy, and the ethylene polymerization and copolymerization activities of the produced POPs-supported metallocene catalysts are higher than their conventional silica gel-supported counterparts; furthermore, the molecular chain structure of the polyolefin could be tailored due to the confinement effect of the nanopores of the POPs-supported catalysts during the process of the olefin polymerization. Therefore, it would be beneficial to design and prepare porous organic polymers with a controlled pore structure and functional groups to incorporate the active sites for olefin polymerization-catalyst supports.

In this work, we have investigated the design and preparation of 2-hydroxypropylmethacrylate (HPMA), glycidyl methacrylate (GMA), vinylbenzyl chloride (VBC), and dual-functional comonomer-functionalized POPs with a controllable pore structure, surface morphology, and bulk densities through a dispersion polymerization strategy. The POPs-supported metallocene catalysts showed excellent ethylene-polymerization activities, and the pore structure of the POPs had significant influence on polymerization activity.

\section{Materials and Methods}

\subsection{Materials}

GMA, HPMA, and 2-hydroxyethylmethacrylate (HEMA) ( $\geq 98 \%$ ) were passed through an oxide aluminum column (neutral) to remove the inhibitor before use. Divinylbenzene $(80 \% / 55 \%$, mixtures of isomers) and styrene ( $\geq 98 \%$ ) were treated with an $\mathrm{NaOH}$ solution $(10 \%$ weight) to remove the inhibitor, and were washed with distilled water until neutralization. VBC $(\geq 97 \%)$ was passed through an active oxide aluminum column before use. 2,2'-Azo-bis-isobutyronitrile (AIBN) ( $\geq 99 \%$ ), poly(vinyl alcohol) (PVA, 1788), iron oxide(II,III) $\left(\mathrm{Fe}_{3} \mathrm{O}_{4}\right)$ nanopowder (99.5\%, $20 \mathrm{~nm}$ beads), and ethanol ( $\left.\geq 99.7 \%\right)$ were used without further purification. All these above agents were purchased from Aladinn Reagent, 
Shanghai, China. Bis (n-butylcyclopentadienyl) zirconium dichloride ((n-BuCp) $\left.{ }_{2} \mathrm{ZrCl}_{2}\right)(\geq 98 \%)$ was purchased from DAL CHEM (Nizhny Novgorod, Russia) and methylaluminoxane (MAO) (10\% toluene solution) was provided from PetroChina, Lanzhou, China and they were used directly as received.

\subsection{Preparation of the Functionalized POP Supports}

Functionalized POP particles were synthesized according to a dispersion polymerization or precipitation polymerization method by previous references [12,35]. Briefly, $130 \mathrm{~mL}$ solvent was charged into a $250 \mathrm{~mL}$ glass reactor, then $5.0 \mathrm{~g}(0.0384 \mathrm{~mol})$ of divinylbenzene (DVB) $(80 \%)$ and 0.0256 mol functional monomer(s) (HEMA, HPMA, GMA, or VBC) and $2 \mathrm{wt} \%$ of PVA were added into the reactor when stirring. After the monomers and the stabilizer were dissolved in the solution, $2 \mathrm{wt} \%$ of the initiator AIBN was added into the reactor to initiate the free-radical polymerization at $70{ }^{\circ} \mathrm{C}$ for 1-4 h. After aging for $3-6 \mathrm{~h}$ at $80^{\circ} \mathrm{C}$, the product was purified by ethanol/distilled water-washing and vacuum-dried for further use. When $\mathrm{Fe}_{3} \mathrm{O}_{4}$ nanopowder was used as a template to prepare the target product, the similar procedure was adopted except that $3 \mathrm{wt} \% \mathrm{Fe}_{3} \mathrm{O}_{4}$ nanoaggregates were added into the reactor before the addition of the initiator AIBN, and that the prepared particles were washed twice with hydrochloric or sulfuric acid for $1-2 \mathrm{~h}$ to remove the template before the products were washed and vacuum-dried to remove impurities.

\subsection{Catalyst Immobilization}

The single-site catalyst was immobilized on the prepared functionalized POPs after they were vacuum-dried. All supporting procedure was free from air and moisture under high-purity nitrogen according to a previous work [35]. Typically, in a $250 \mathrm{~mL}$ glass reactor, $3.0 \mathrm{~g}$ treated functionalized POP particles and $80 \mathrm{~mL}$ toluene, and a $20 \mathrm{~mL}$ MAO solution were charged into the reactor and stirred at ambient temperature for $1-2 \mathrm{~h}$. Then, $0.30 \mathrm{mmol}(\mathrm{n}-\mathrm{BuCp})_{2} \mathrm{ZrCl}_{2}$ was added to the MAO-treated POPs, and the suspension was kept stirring at $-20^{\circ} \mathrm{C}$ for $2-3 \mathrm{~h}$. Then, the obtained solid was washed and vacuum-dried to get the final supported metallocene catalyst.

\subsection{Characterization}

Nitrogen sorption was analyzed on a Nova 2000e (Quantachrome Instruments, Boynton Beach, FL, USA) at liquid nitrogen $(77.3 \mathrm{~K})$. The POP samples were tested in a glass tube before the samples were vacuum-dried at $120{ }^{\circ} \mathrm{C}$ for $12 \mathrm{~h}$ to remove adsorbed materials, and the supported catalysts were directly tested under $\mathrm{N}_{2}$ protection without heating for desorption. $\mathrm{Al}$ and $\mathrm{Zr}$ loading of the supported catalysts were performed on a VISTA ICP-MPX (VARIAN, Palo Alto, CA, USA). $0.1 \mathrm{~g}$ catalyst was dissolved in a $10 \mathrm{~mL}$ aqua regia by heating, and then the solution was metered to $100 \mathrm{~mL}$ constant volume using $2 \% \mathrm{HCl}$ solution. $\mathrm{Al}$ and $\mathrm{Zr}$ loading contents were obtained by the standard curves of their characteristic peaks. IR analysis was performed on a NEXUS 670 FTIR (Glendale, WI, USA). The surface morphology of the POP samples was conducted on a scanning electron microscope (SEM, Philips, XL20, Amsterdam, The Netherlands). The functionalized POP samples were mounted on electric glue, then sprayed with a thin layer of gold in vacuum before testing.

\section{Results and Discussion}

\subsection{Preparation of Poly(divinylbenzene) (PDVB)-Based Functionalized Porous Organic Polymers}

In this work, the emphasis focus on the design and synthesis of potential DVB-based porous organic polymer supports with different functional comonomers for metallocene catalysts by a dispersion polymerization method [12,35], and the suitable polymer supports, like the inorganic counterparts, generally contain relatively high specific surface area (SSA) and porosity (SSA $\geq 100 \mathrm{~m}^{2} \cdot \mathrm{g}^{-1}, \quad \mathrm{PV} \geq 0.2 \mathrm{~cm}^{3} \cdot \mathrm{g}^{-1}$ ) with good morphology and suitable bulk density $\left(0.2-0.4 \mathrm{~g} \cdot \mathrm{cm}^{-3}\right)$. A series of functionalized PDVB-based POP particles were prepared using St, HEMA, HPMA, GMA, and VBC as comonomers. 
The schematic illustration of synthesis of functionalized PDVB particles is shown in Figure 1. The porosity results based on $\mathrm{N}_{2}$ sorption results and bulk density are listed in Table 1 . Non Local Density Functional Theory (NLDFT or DFT) simulation was adopted using $\mathrm{N}_{2}$-carbon kernel at $77 \mathrm{~K}$ based on a slit-pore model to evaluate the pore textural structure, especially the pore-size distribution of the prepared POP samples.

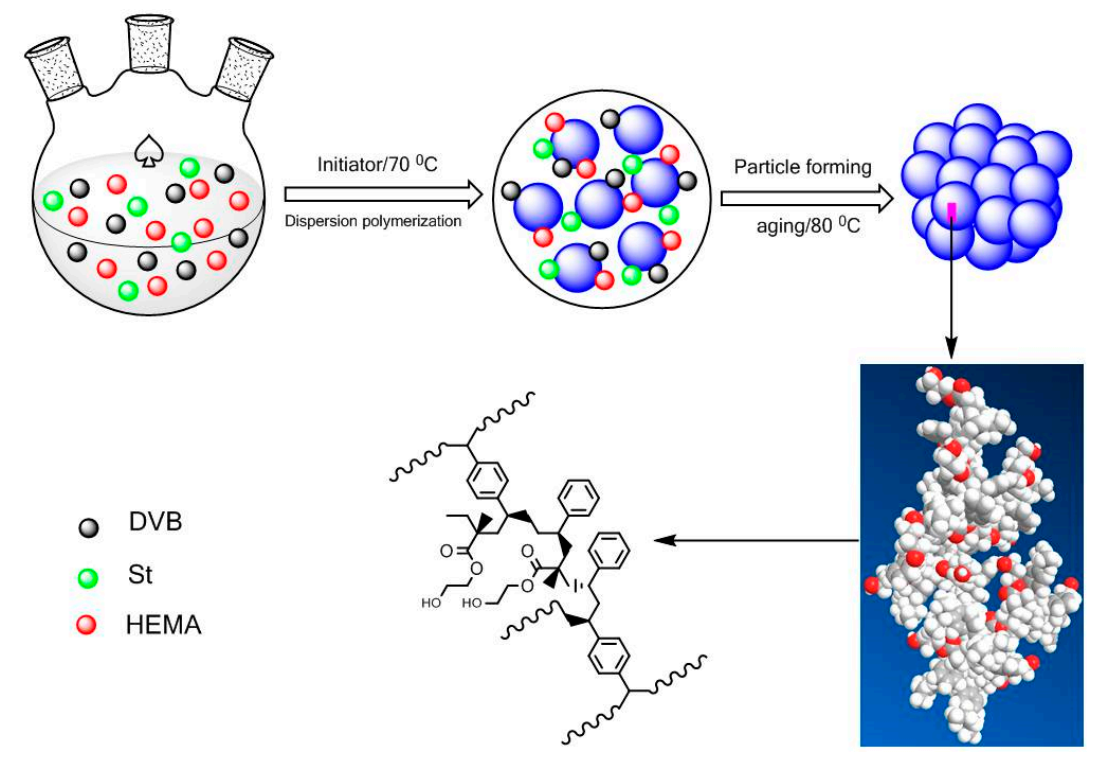

Figure 1. Schematic illustration of synthesis of functionalized PDVB particles. 
Table 1. Characterization of poly(divinylbenzene) (PDVB)-based functional polymer from $\mathrm{N}_{2}$ sorption results and bulk density.

\begin{tabular}{|c|c|c|c|c|c|c|c|c|c|}
\hline No. & $\begin{array}{c}\text { Functional } \\
\text { Comonomer (FC) }\end{array}$ & Solvent & $\begin{array}{l}\text { Divinylbenzene } \\
\text { (DVB) }\end{array}$ & $\begin{array}{c}\text { FC/DVB } \\
\text { (Molar Ratio) }\end{array}$ & $\begin{array}{l}\text { Template } \\
\text { Agent }\end{array}$ & $\begin{array}{c}\text { Specific Surface } \\
\text { Area(Multi Point } \\
\text { BET) }\left[\mathrm{m}^{2} / \mathrm{g}\right]\end{array}$ & $\begin{array}{c}\text { Total Pore } \\
\text { Volume } \\
{\left[\mathrm{cm}^{3} / \mathrm{g}\right]}\end{array}$ & $\begin{array}{c}\text { Average Pore } \\
\text { Diameter } \\
\text { [nm] }\end{array}$ & $\begin{array}{l}\text { Bulk Density } \\
\mathrm{g} / \mathrm{cm}^{3}\end{array}$ \\
\hline 1 & St & $\mathrm{EtOH} / \mathrm{H}_{2} \mathrm{O}=10: 1$ & $55 \%$ & $5: 4$ & - & 41.6 & 0.0836 & 8.03 & 0.08 \\
\hline 2 & - & $\mathrm{EtOH} / \mathrm{H}_{2} \mathrm{O}=9: 1$ & $80 \%$ & - & - & 178 & 0.396 & 8.89 & 0.02 \\
\hline 3 & HEMA & $\mathrm{EtOH} / \mathrm{H}_{2} \mathrm{O}=9: 1$ & $80 \%$ & $2: 3$ & - & 417 & 0.434 & 4.16 & 0.20 \\
\hline 4 & HPMA & $\mathrm{EtOH} / \mathrm{H}_{2} \mathrm{O}=9: 1$ & $80 \%$ & $2: 3$ & - & 430 & 0.447 & 4.16 & 0.24 \\
\hline 5 & GMA & $\mathrm{EtOH} / \mathrm{H}_{2} \mathrm{O}=9: 1$ & $80 \%$ & $3: 5$ & - & 17.1 & 0.040 & 9.34 & 0.08 \\
\hline 6 & VBC & $\mathrm{EtOH} / \mathrm{H}_{2} \mathrm{O}=9: 1$ & $80 \%$ & $0.52: 1$ & - & 50.9 & 0.104 & 8.21 & 0.05 \\
\hline $7-1$ & HPMA & $\mathrm{EtOH} / \mathrm{H}_{2} \mathrm{O}=9: 1$ & $80 \%$ & $2: 3$ & $\begin{array}{c}\mathrm{Fe}_{3} \mathrm{O}_{4}-20 \mathrm{~nm} \\
3 \mathrm{wt} \%\end{array}$ & 412 & 0.420 & 4.08 & 0.25 \\
\hline $7-2$ & & & & & - & 441 & 0.480 & 4.35 & 0.24 \\
\hline $8-1$ & $\begin{array}{l}\text { HEMA/St } \\
\text { (FC1/FC2) }\end{array}$ & $\mathrm{EtOH} / \mathrm{H}_{2} \mathrm{O}=9: 1$ & $80 \%$ & $\begin{array}{l}\text { FC1/FC2/DVB } \\
=1.0 / 0.7 / 1.15\end{array}$ & $\begin{array}{c}\mathrm{Fe}_{3} \mathrm{O}_{4}-20 \mathrm{~nm} \\
3 \mathrm{wt} \%\end{array}$ & 199 & 0.299 & 6.01 & 0.30 \\
\hline $8-2$ & & & & & & 215 & 0.301 & 5.59 & 0.29 \\
\hline 9 & $\begin{array}{l}\text { HEMA/St } \\
\text { (FC1/FC2) }\end{array}$ & $\mathrm{EtOH} / \mathrm{H}_{2} \mathrm{O}=9: 1$ & $80 \%$ & $1.0 / 0.7 / 1.15$ & - & 183 & 0.296 & 6.45 & 0.22 \\
\hline 10 & HEMA/VBC & $\mathrm{EtOH} / \mathrm{H}_{2} \mathrm{O}=9: 1$ & $80 \%$ & 1:0.29:1.5 & - & 90.8 & 0.122 & 5.32 & 0.16 \\
\hline 11 & HEMA/VBC & $\mathrm{EtOH} / \mathrm{H}_{2} \mathrm{O}=9: 1$ & $80 \%$ & $1: 0.56: 1.19 * a$ & - & 15.1 & 0.0383 & 10.1 & 0.39 \\
\hline 12 & HEMA/VBC & ethanol & $80 \%$ & $1: 0.32: 1.19 * a$ & & 4.88 & 0.0131 & 10.7 & 0.33 \\
\hline 13 & HEMA/VBC & ethanol & $80 \%$ & 1:0.147:1.19 & - & 210 & 0.244 & 4.63 & 0.28 \\
\hline 14 & HEMA/VBC & ethanol & $80 \%$ & 1:0.17:1.5 & - & 380 & 0.400 & 4.21 & 0.22 \\
\hline
\end{tabular}

*a The reaction solution after stirring is not homogeneous system due to bad thermal compatibility. HEMA: 2-hydroxyethylmethacrylate; HPMA: 2-hydroxypropylmethacrylate; GMA: glycidyl methacrylate; VBC: vinylbenzyl chloride. 


\subsection{The Influence of Functional Comonomers on the Pore Structure of POPs}

The influence of functional comonomers on the formation of a nanoporous structure was investigated firstly. As shown in Figure 2, quite different $\mathrm{N}_{2}$ sorption isotherms (Samples 1, 3, 4, 5, and 6 with St, HEMA, HPMA, GMA, VBC as functional comonomers, respectively, and Sample 2: DVB only) mean that quite different porous structure were produced by dispersion polymerization in ethanol/deionized water $(\mathrm{V}: \mathrm{V}=9: 1)$ from these different functional comonomers. The PDVB-based POPs prepared with functional comonomers such as HEMA and HPMA are highly porous, and the PDVB without other functional comonomers is moderately porous, while the POPs synthesized with GMA, VBC, and St (actually with no other functional group and non-cross-linking ability compared with DVB) are poorly porous. Therefore, the type of the chosen functional comonomer in the synthesis is an important factor of tuning the pore structure of prepared POPs. From the nitrogen sorption isotherms of these functional POPs, we can also reasonably infer that two major factors of the used comonomers could influence the porous structure of the prepared POPs. The first one is the functional group on the selected comonomer; the polarity of the prepared POPs were changed when changing the functional comonomer, which would vary the thermal compatibility between the prepared POPs with the solvent system, and the porous structure could be adjusted by the thermodynamic compatibility. Generally, a highly porous structure was produced from a thermodynamic compatible system, and a nonporous structure was generated from systems with bad thermodynamic compatibility, which could be explained by the classical pore-formation mechanism of porous polymer microspheres. The second factor is the cross-linking content in the prepared functional POPs; when a kind of functional comonomer with only one polymerizable double bond is added, the cross-linking degree is actually decrease.

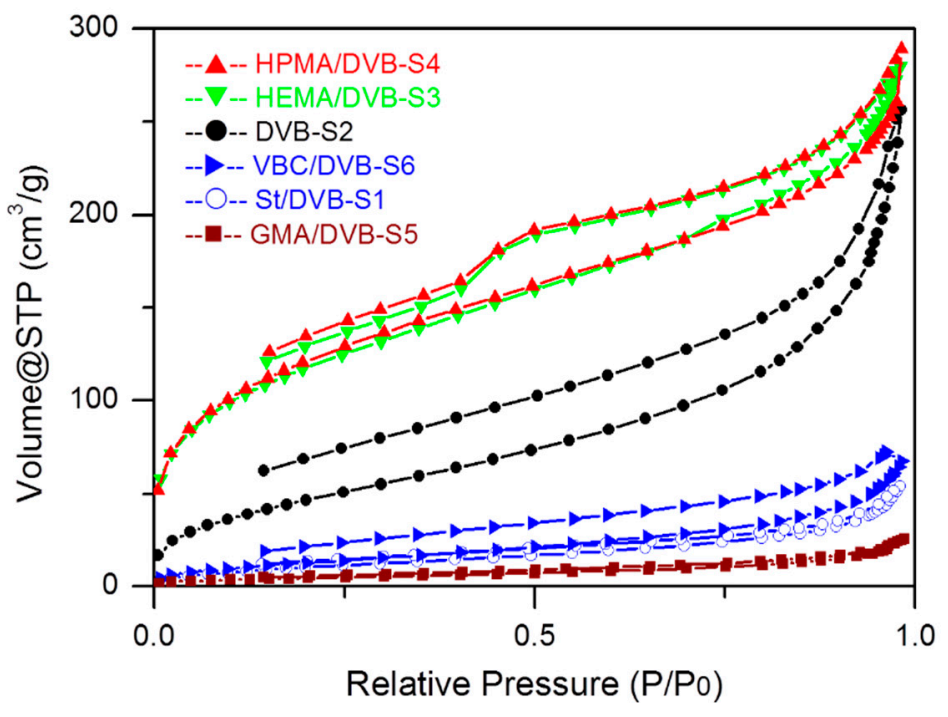

Figure 2. $\mathrm{N}_{2}$ sorption isotherms of porous organic polymers synthesized with different functional comonomers.

Due to the amorphous nature of the prepared functional POPs, which make it impossible to characterize by X-ray crystallography, an NLDFT simulation was used to evaluate the pore size and pore-size distribution of these POPs. From Figure 3, we can see that the pore-size abundance of these POPs mainly focuses on a relatively wide range from 1 to $10 \mathrm{~nm}$, except that GMA and styrene as comonomers resulted in nearly nonporous materials. HPMA and HEMA-functionalized PDVB are highly porous with well-defined cavities mainly scattering in micropores and narrow mesopores from 1.1 to $4.5 \mathrm{~nm}$, and the cumulative SSA and PV of the HPMA- and HEMA-functionalized PDVB are about $250 \mathrm{~m}^{2} / \mathrm{g}$ and $0.264 \mathrm{~cm}^{3} / \mathrm{g}$, and $240 \mathrm{~m}^{2} / \mathrm{g}$ and $0.256 \mathrm{~cm}^{3} / \mathrm{g}$, respectively. The mode value (the 
highest peak) of pore diameter from the NLDFT analysis of the HPMA-functionalized PDVB is $1.3 \mathrm{~nm}$ in the range of micropores in the SSA and PV pore-size-distribution curves, and the mode values of pore diameter of HEMA-functionalized PDVB are $1.4 \mathrm{~nm}$ in the pore-size distribution of SSA and $2.2 \mathrm{~nm}$ in the pore-size distribution of PV in the range of micropores and narrow mesopores. Furthermore, we can see the larger pore size from above $4.5 \mathrm{~nm}$ contributes more to total pore volume than surface area. In contrast, the mode value of pore diameter of the VBC-functionalized PDVB is about $2.1 \mathrm{~nm}$, which is similar to that of the PDVB, and the similar pore-size distribution could be explained by their approximate solubility parameters, and the decrease of abundance of pore-size distribution, despite similar pore-size distribution, could be explained by the worse thermal compatibility of VBC with the mixture solvent and the decrease of cross-linking degree by adding the non-cross-linking functional comonomer VBC.

(a)
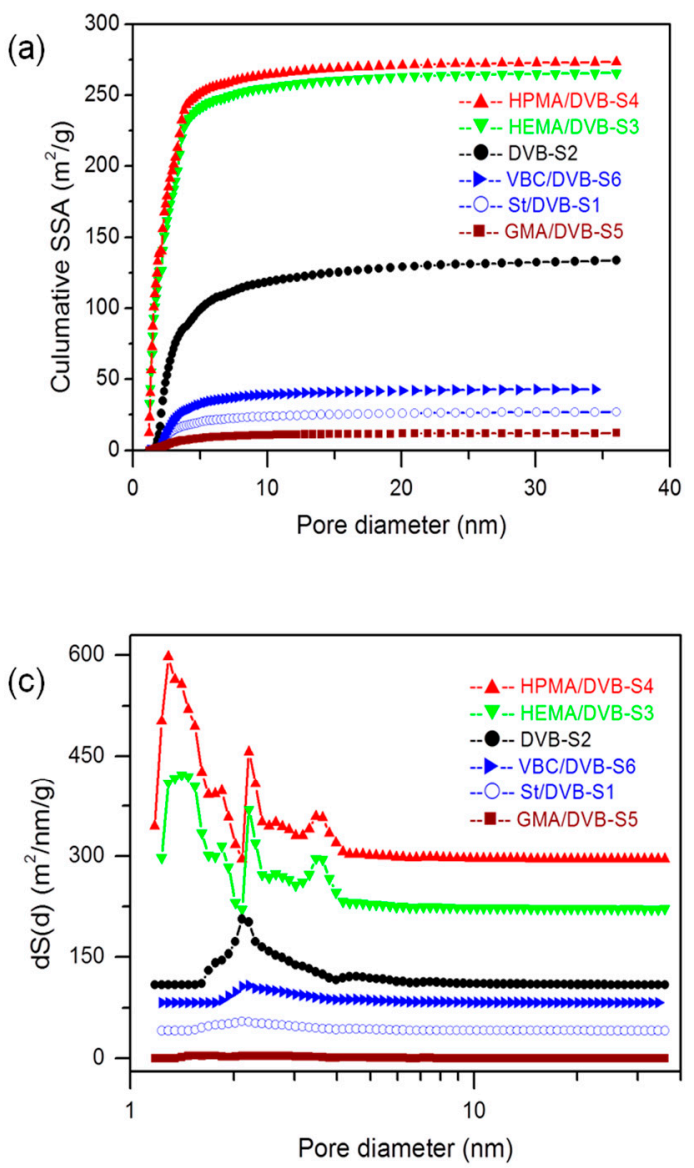
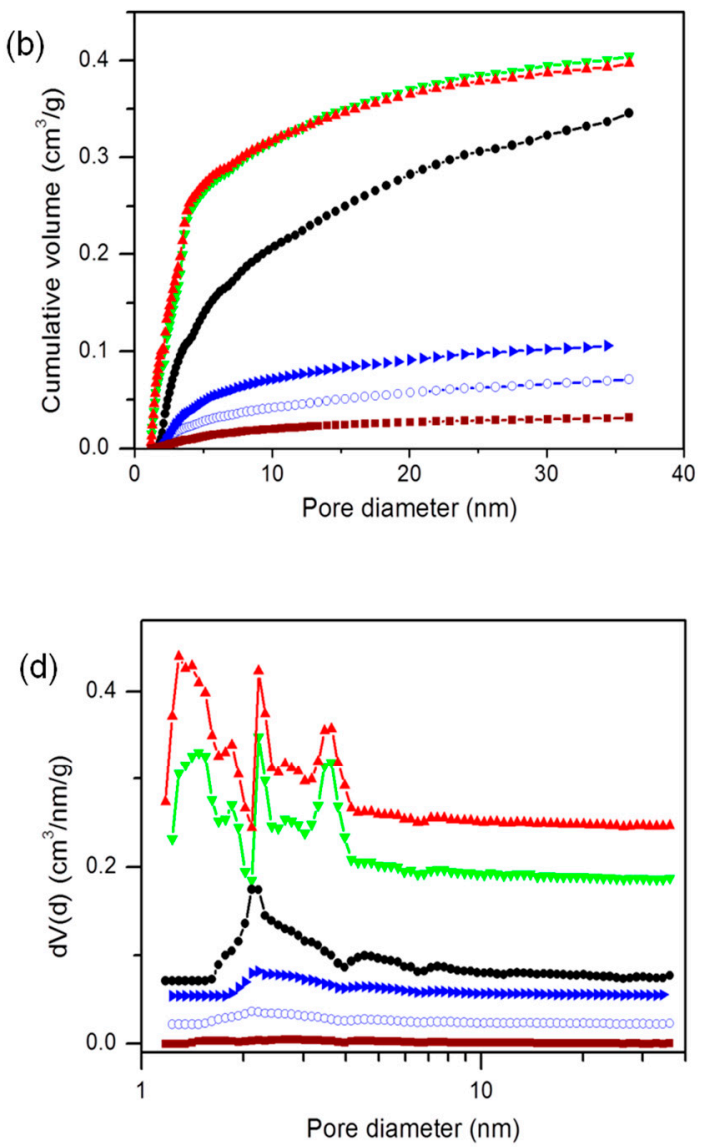

Figure 3. Non Local Density Functional Theory (NLDFT) simulation of pore structure of different functionalized PDVB-based POPs. (a) Cumulative specific surface area (SSA) curves, (b) porosity (PV) curves, (c) pore-size-distribution curves of $d S(d)$ vs. $d$ and (d) dV(d) vs. $d$.

As shown in Table 1, HEMA and HPMA are good functional comonomers to prepare porous polymers for catalyst support, with the highly porous structure of Sample 3 (SSA $=417 \mathrm{~m}^{2} / \mathrm{g}$, $\left.\mathrm{PV}=0.434 \mathrm{~cm}^{3} / \mathrm{g}\right)$ and Sample $4\left(\mathrm{SSA}=430 \mathrm{~m}^{2} / \mathrm{g}, \mathrm{PV}=0.447 \mathrm{~cm}^{3} / \mathrm{g}\right)$, while VBC, St, and GMA are typically bad for synthesis of porous polymers, at least in this mixture solvent, and they also cause low bulk density $\left(<0.1 \mathrm{~g} / \mathrm{cm}^{3}\right)$ due to their poor thermal compatibility with the dispersion solvent. From the above pore-size-distribution curves, we can also reasonably conclude that the increase of average pore diameter from about $4 \mathrm{~nm}$ to $8 \mathrm{~nm}$ of poorly porous polymers is caused mainly by the decrease of abundance of pore-size distribution in the range of micropores and narrow mesopores. 


\subsection{The Synthesis of PDVB-Based POPs with Dual Functional Comonomers}

Two functional comonomers, HEMA and VBC (or styrene), with different thermal compatibility with the dispersion solvent were used to tune the pore structure, bulk density, and particle morphology. The pore structure of the prepared PDVB-based POPs with dual functional comonomers could be controllable by tuning the HEMA/VBC/DVB molar ratio. Three samples of POPs (Samples 12, 13, and 14) were synthesized in different HEMA/VBC/DVB molar ratios, and three types of nitrogen isotherms were obtained as seen in Figure 4. When the functional comonomer VBC was in a relatively high molar ratio, the comonomer systems are inhomogeneous in ethanol dispersion solvent due to the bad solubility of VBC, so Sample 12 wasn't synthesized in dispersion polymerization, but in suspension polymerization, and nonporous isotherm was obtained with relatively high bulk density $0.33 \mathrm{~g} / \mathrm{cm}^{3}$. By decreasing the VBC molar ratio, the HEMA/VBC/DVB systems could be homogeneously dispersed in ethanol, and porous isotherms were obtained in Samples 13 and 14.

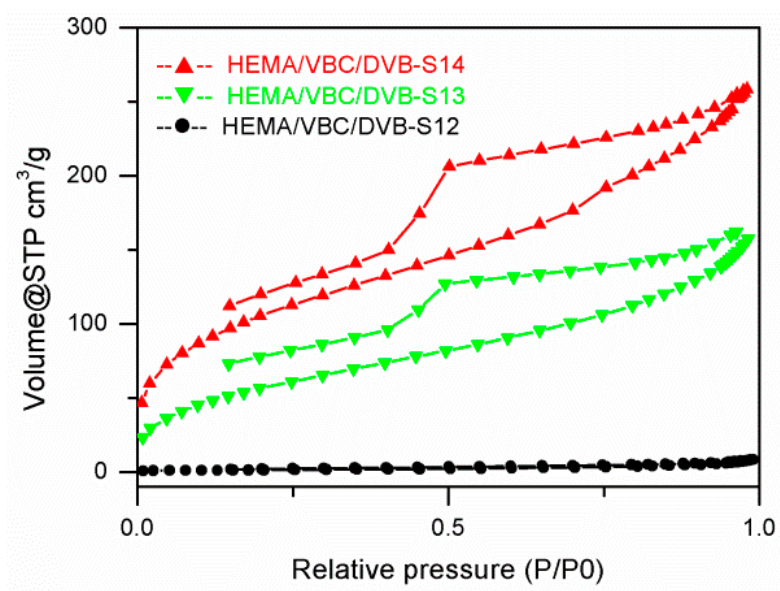

Figure 4. $\mathrm{N}_{2}$ sorption isotherms of POPs synthesized with different HEMA/VBC/DVB molar ratio.

Comparing Sample 13 with Sample 14 prepared in dispersion polymerization, we could see that the PDVB-based POPs with dual functional comonomers HEMA and VBC have a similar pore structure with characteristic peaks (around 1.3, 2.2, and $3.8 \mathrm{~nm}$ right shift compared with S3/S4 of $3.6 \mathrm{~nm}$ in this peak) in their pore-size-distribution curves as, in the HEMA-functionalized PDVB, the HEMA content or VBC added in ethanol could be used to tune the abundance in triple peaks of pore distribution. From Figure 5, when decreasing the overall content of HEMA (cross-linking degree in the prepared POPs increased actually), the abundance in the micropores and narrow mesopores (roughly 1-5 nm) increases. The SSA and PV witness a rapid increase from Sample 13 with SSA of $210 \mathrm{~m}^{2} / \mathrm{g}$, $\mathrm{PV}$ of $0.244 \mathrm{~cm}^{3} / \mathrm{g}$ to Sample 14 with SSA of $380 \mathrm{~m}^{2} / \mathrm{g}$, PV of $0.400 \mathrm{~cm}^{3} / \mathrm{g}$. Another important role that the dual functional comonomers played is that this dual functional comonomer system could adjust the bulk density and morphology of prepared POPs. As seen in Table 1, the bulk density of Sample 13 had a relatively high bulk density of $0.28 \mathrm{~cm}^{3} / \mathrm{g}$, which is hard to obtain using a HEMA/DVB comonomer system given no other template agent was added. We will discuss the morphology of the prepared POPs in detail later. 

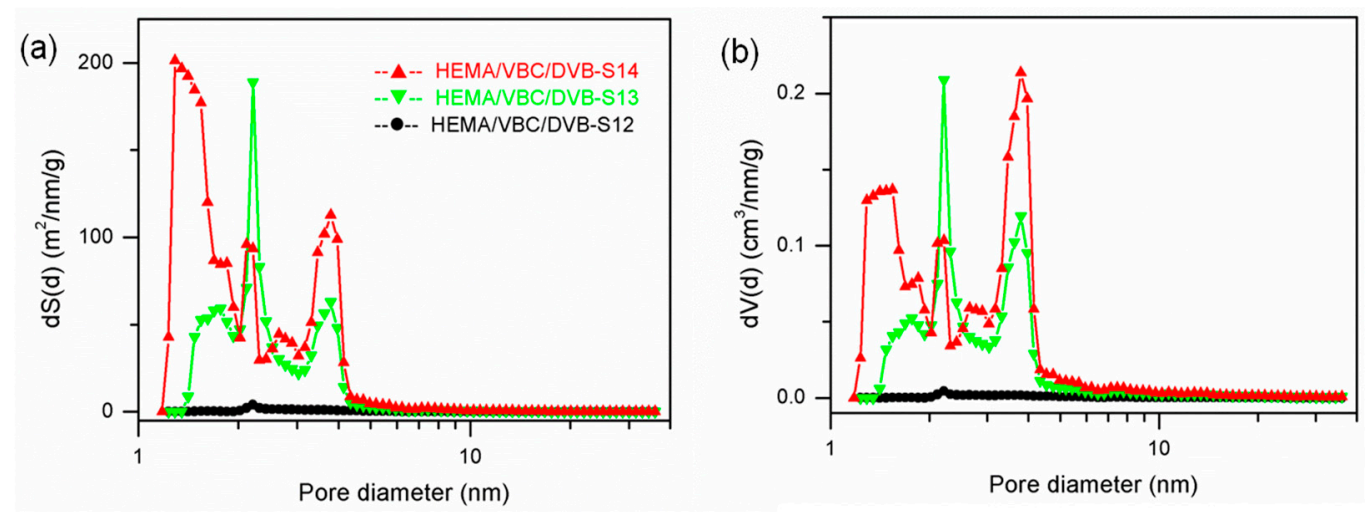

Figure 5. NLDFT simulation of pore structure of POPs (Samples 12/13/14) from dual functional comonomers. (a) Pore-size-distribution curves of dS(d) vs. d and (b) dV(d) vs. d.

\subsection{The Influence of a Template Agent on the Pore Structure of POPs}

We have reported in our previous research [12] that the template agent is a useful tool to tune the pore structure, bulk density, and morphology of the prepared POPs. In the prepared PDVB-based POPs with dual functional comonomers HEMA and styrene, iron oxide (II, III) aggregates of $20 \mathrm{~nm}$ were used as a template to tune their pore structure and morphology. As seen in Table 1, the iron oxide (II, III) template could help to improve the specific surface area and the total volume in the HEMA/St/DVB system (Samples 8-2 and 9), increasing the SSA from 183 to $215 \mathrm{~m}^{2} / \mathrm{g}$ and the PV from 0.296 to $0.301 \mathrm{~cm}^{3} / \mathrm{g}$. Furthermore, the bulk density of the prepared poly(HEMA-co-St-co-DVB) particles increased obviously from 0.22 to $0.29 \mathrm{~g} / \mathrm{cm}^{3}$. As we explained, the particle-forming mechanism using a template agent in our previous work [12], when a hydrophilic metal oxide was used as a template agent, the hydrophilic functional comonomers would adsorb on the interfaces of nanoaggregates of the iron oxide (II, III). After a free-radical initiator initialized the copolymerization on their interfaces, the poly(HEMA-co-St-co-DVB) particles were prepared around the nanoaggregates of iron oxide (II, III). As the HEMA, styrene, and DVB monomers continued to diffuse and polymerize on the surface of the metal oxide, the POP particles continuingly grew larger and finally the metal oxide or nanoaggregates were dispersed in the matrix of the prepared POPs. After acid etching, the metal oxide was removed and the final POPs were obtained. From Figure 6, we can observe an overall increase of SSA and PV of Sample 8-2 when the nanoaggregates of iron oxide (II, III) in Sample 8-1 was removed, while the pore-size-distribution curves of the three samples (8-1/8-2/9) kept similar. These results could be reasonably explained by this proposed particle-forming mechanism of the template agent. Similar results are also observed when the nanoaggregates of iron oxide (II, III) were used as a template agent in the synthesis of poly(HPMA-co-DVB) particles (see Samples 7-1/7-2/4). 

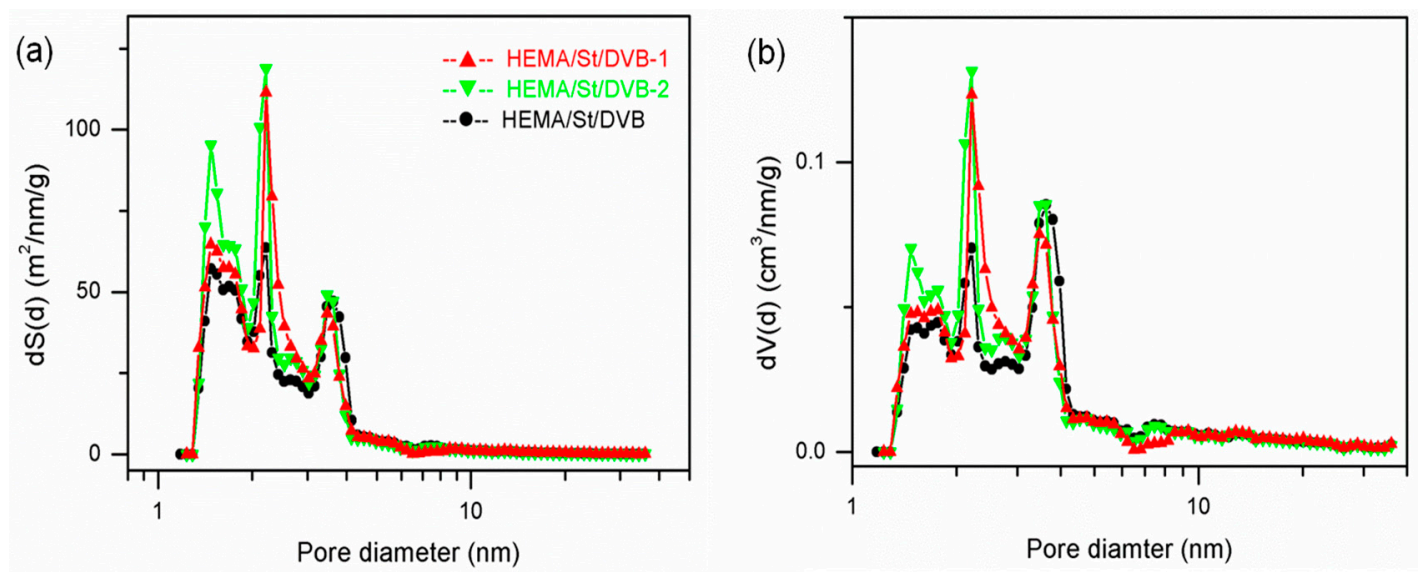

Figure 6. NLDFT simulation of the pore structure of POPs (Samples 8-1/8-2/9) from template methods.

(a) Pore size distribution curves of $\mathrm{dS}(\mathrm{d})$ vs. $\mathrm{d}$ and (b) $\mathrm{dV}(\mathrm{d})$ vs. $\mathrm{d}$.

\subsection{Cross-Linking Degree and Solvent on the Pore Structure of POPs}

As discussed above, the cross-linking degree of the prepared POPs could be identified as an important factor to tune the pore structure of the amorphous POPs. The solubility parameters of St and DVB (55\% and $80 \%)$ are very close, and their chemical properties are also similar to each other, except their cross-linking degree produced in the POPs. When decreasing the content of cross-linking degree from DVB (80\%) to St/DVB (55\%) (5:4), as seen from Samples 1 and 2 (DVB only) in Figures 2 and 3, Sample 1 became less porous and the characteristic peak around $2.1 \mathrm{~nm}$ in the pore-size distribution decreased dramatically compared to the highly cross-linked PDVB networks.

The solvent system used was also a key factor in influencing the pore size and the pore-size distribution, the bulk density, and surface morphology of the target polymer. This factor was discussed in detail in our previous work [35]; the pore structure and morphology of the prepared polymer are highly related with the thermodynamic compatibility evaluated by the difference of the solubility parameters between the polymer and the solvent system. Typically, it is very important to match the functional comonomers/DVB system with suitable solvent(s) in the design and synthesis of potential POPs as suitable metallocene-catalyst support.

\subsection{IR Analysis}

The IR spectra of the five prepared functionalized PDVB samples $(1,5,7-2,12$, and 14 with St, GMA, HPMA, HEMA/VBC, and HEMA/VBC as functional comonomers, respectively) are shown in Figure 7. We can observe that the bands in 1450 and in $2930 \mathrm{~cm}^{-1}$ exist in all these samples which is the inplane-bending or twist-bending mode, and the stretching vibration of $\widetilde{\mathbf{v}}(\mathrm{C}-\mathrm{H})$ of methylene $\left(-\mathrm{CH}_{2}-\right)$, respectively. The peak around $1725 \mathrm{~cm}^{-1}$ is the sketching mode of $\mathrm{C}=\mathrm{O}$ in the 4 samples (5, 7-2, 12, and 14) with GMA, HPMA, and HEMA units in their own network. Generally, the bands in 1450 and in $2930 \mathrm{~cm}^{-1}$ can be used to calibrate relative content of the $\mathrm{C}=\mathrm{O}$ functional group in these functionalized PDVB samples by peak area or peak height contrast with the peak around $1725 \mathrm{~cm}^{-1}[38,39]$. Furthermore, the peak in $3030 \mathrm{~cm}^{-1}$ due to the stretching vibration mode of $\widetilde{\mathbf{v}}(\mathrm{C}-\mathrm{H})$ inbenzene was observed obviously in the P(St-co-DVB) Sample 1. In the GMA-functionalized PDVB (Sample 5), except from the peak around $1725 \mathrm{~cm}^{-1}$, the bands around 910 and $845 \mathrm{~cm}^{-1}$ were also observed, which are the characteristic peaks of the asymmetic vibration of the epoxy group of GMA units, and the lack of absorbance in the range from 3600 to $3200 \mathrm{~cm}^{-1}$ proved that GMA units are incorporated into the $\mathrm{P}(\mathrm{GMA}-\mathrm{co}-\mathrm{DVB})$ network by $\mathrm{C}=\mathrm{C}$ double bond, not by ring-opening polymerization of the epoxy group in GMA. In the P(HEMA-co-DVB-co-VBC) systems (Samples 12 and 14), the peak around $1265 \mathrm{~cm}^{-1}$ could be attributed to the characteristic absorption peak of methyl 
chloride linked to benzene ring, and this peak was stronger in Sample 12 than in Sample 14 due to the higher adding ratio of the VBC comonomer.

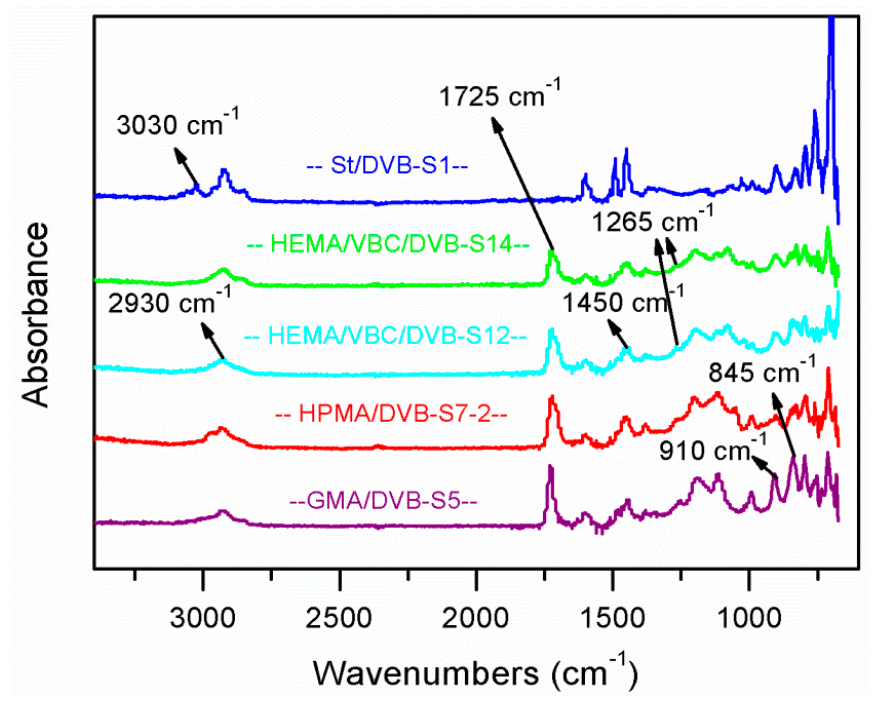

Figure 7. IR spectra of the prepared POPs with different functional comonomers.

\subsection{Bulk Density and Surface Morphology of the POPS}

By the design of the PDVB-based functionalized POPs with varied functional comonomer(s), template agent, and solvents, a wide range of bulk density of the prepared POPs $\left(0.02-0.39 \mathrm{~g} / \mathrm{cm}^{3}\right)$ could be obtained as seen from Table 1 . In the ethanol/deionized water (9:1) mixture solvents, styrene, VBC, GMA, and DVB and their own polymer networks exhibited bad thermodynamic compatibility with the solvents system, which caused the early-phase separation of the prepared POPs and low bulk density $\left(0.02-0.08 \mathrm{~g} / \mathrm{cm}^{3}\right)$. The SEM images of representative POPs were shown in Figure 8 . From Figure 8, we can see that the $\mathrm{P}(\mathrm{St}$-co-DVB) and the $\mathrm{P}(\mathrm{DVB})$ particles consist of aggregates of nano-microspheres and their low bulk density was caused by fluffy stacking of the microspheres. When HEMA and HPMA functional comonomers were incorporated into the PDVB networks, the bulk density of the P(HEMA-co-DVB) and P(HPMA-co-DVB) particles increased dramatically, from 0.02 to above $0.20 \mathrm{~g} / \mathrm{cm}^{3}$, due to their good thermodynamic compatibility with the same solvents system, and the SEM image of S3 proved that the dramatic increase of bulk density was due to the compact stacking of the microspheres. Furthermore, when the HEMA functional comonomer was incorporated into the $\mathrm{P}(\mathrm{St}-\mathrm{co}-\mathrm{DVB})$ or $\mathrm{P}(\mathrm{VBC}-\mathrm{co}-\mathrm{DVB})$ networks, it could also help improve the thermodynamic compatibility with the selected solvents system; the prepared P(HEMA-co-St-co-DVB) or P(HEMA-co-VBC-co-DVB) particles obtained relatively high bulk density $\left(0.16-0.28 \mathrm{~g} / \mathrm{cm}^{3}\right) \mathrm{by}$ dispersion polymerization. As seen from the SEM image of Sample 14, the highly porous structure and compact stacking of the aggregates was observed due to their good thermodynamic compatibility with the chosen solvents. Samples 11 and 12 were prepared in an inhomogeneous system due to the bad solubility of VBC in the used solvents system, and higher bulk density $\left(0.33-0.39 \mathrm{~g} / \mathrm{cm}^{3}\right) \mathrm{was}$ obtained with a bad porous structure (Figure $8 \mathrm{e}, \mathrm{f}$ ) in suspension polymerization. 

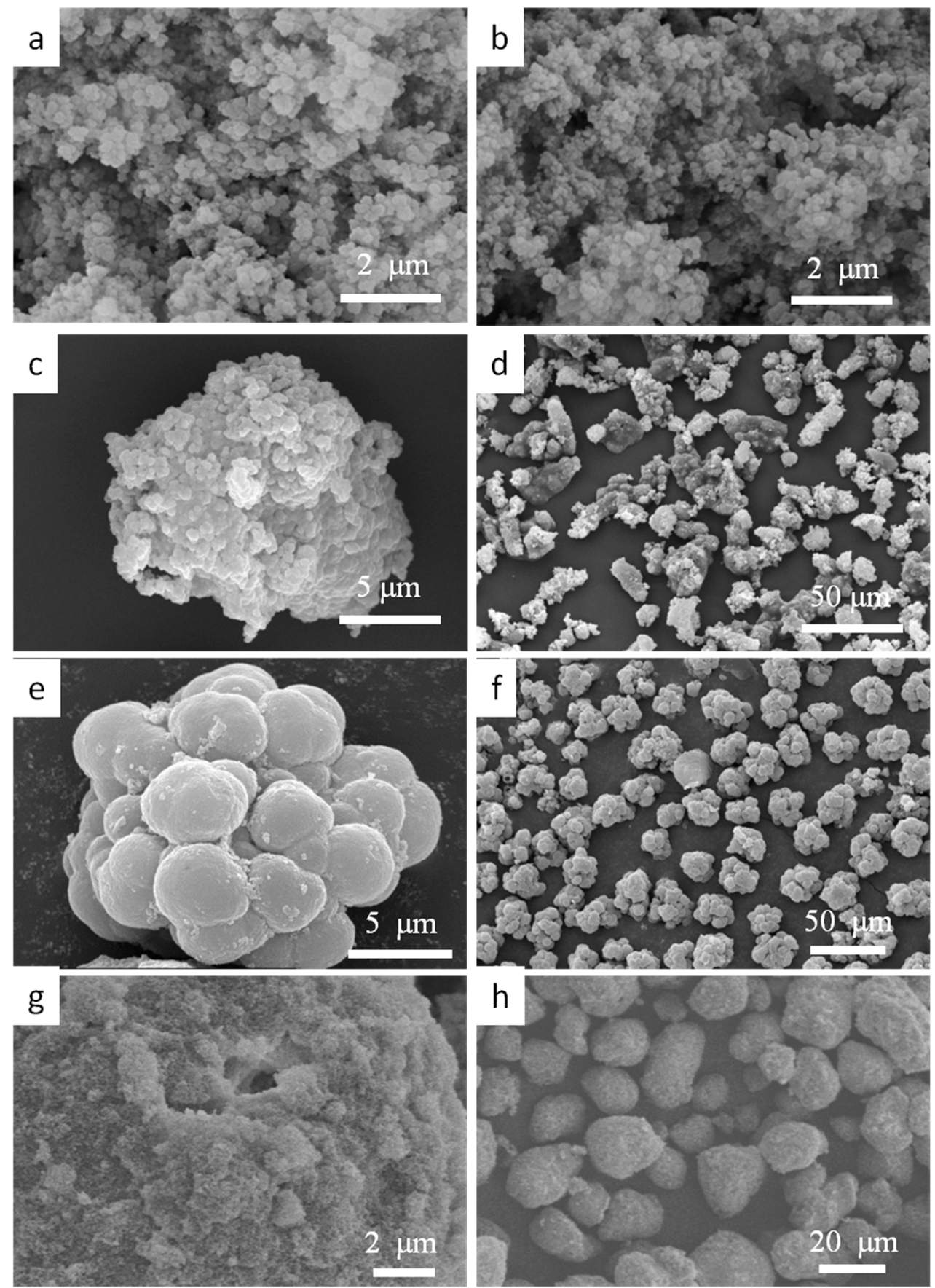

Figure 8. Scanning electron microscope images of functionalized POP particles. (a) The P(DVB) particles of Sample 2, (b) the P(st-co-DVB) particles of Sample 1, (c,d) the P(HEMA-co-DVB) particles of Sample 3, (e,f) the P(HEMA-co-VBC-co-DVB) particles of Sample 11, (g,h) the P(HEMA-co-VBC-co-DVB) particles of Sample 14.

\subsection{Ethylene Polymerization of Supported Metallocene Catalysts}

The metallocene-catalyst systems $\left((\mathrm{n}-\mathrm{BuCp})_{2} \mathrm{ZrCl}_{2} / \mathrm{MAO}\right)$ were immobilized on the prepared PDVB-based POPs, then the supported (n-BuCp) ${ }_{2} \mathrm{ZrCl}_{2} / \mathrm{MAO} @ P O P s$ catalysts were evaluated for ethylene polymerization in a slurry process reactor. The supported catalysts were characterized for zirconium- and aluminium-loading content, and the results of $\mathrm{Zr}, \mathrm{Al} / \mathrm{Zr}$ (molar ratio) and ethylene polymerization were shown in Table 2. From Table 2, we can see that quite different $\mathrm{Zr}$ 
and $\mathrm{Al} / \mathrm{Zr}$ values were obtained, and the $\mathrm{Zr}$ - and $\mathrm{Al}$-loading content were highly dependent on the pore structure of the prepared POPs, when MAO can be effectively immobilized on the surface of the prepared functionalized POPs. High loading content of $\mathrm{Zr}$ and Al were obtained on highly porous POPs-Samples 4 and 14 with SSA of 430 and $380 \mathrm{~m}^{2} / \mathrm{g}$, respectively, while low loading content $\mathrm{Zr}$ and $\mathrm{Al}$ were obtained on badly porous POPs-Samples 5 and 12 with SSA of 17.1 and $4.88 \mathrm{~m}^{2} / \mathrm{g}$, respectively. The ethylene-polymerization results show that high polymerization activity and productivity were obtained on the immobilized catalysts with a high $\mathrm{Zr}$ loading content and $\mathrm{Al} / \mathrm{Zr}$ molar ratio. Samples 4 and 14-supported catalysts obtained high polymerization of 8033 and $7152 \mathrm{~kg}$ $\mathrm{PE} / \mathrm{mol} \mathrm{Zr}$ h bar, respectively. Compared with Sample 4, Sample 5-supported catalysts obtained low polymerization activity and productivity due to low $\mathrm{Al} / \mathrm{Zr}$ - and $\mathrm{Zr}$-loading content, and the Sample 12-supported catalyst exhibited no polymerization activity due to near lack of $\mathrm{Zr}$ loading on its badly porous surface.

The bulk density of the obtained PE could be explained by the replicating mechanism of the polyethylene on the support in the polymerization process proposed by Fink and coworkers $[40,41]$. The higher the bulk density of the prepared POPs is, the higher the bulk density of the obtained PE from them can be achieved. The PE from Sample $4\left(0.24 \mathrm{~g} / \mathrm{cm}^{3}\right)$ obtained the highest bulk density of $0.30 \mathrm{~g} / \mathrm{cm}^{3}$, while the PE from Sample $5\left(0.08 \mathrm{~g} / \mathrm{cm}^{3}\right)$ obtained the lowest bulk density of $0.11 \mathrm{~g} / \mathrm{cm}^{3}$.

Table 2. Ethylene polymerization results (catalyst: (n-BuCp) $\left.{ }_{2} \mathrm{ZrCl}_{2} / \mathrm{MAO} @ \mathrm{POPs}\right) * \mathrm{~b}$.

\begin{tabular}{|c|c|c|c|c|c|c|c|}
\hline No. & $\begin{array}{c}\mathrm{Zr} \\
(\mu \mathrm{mol} / \mathrm{g})\end{array}$ & $\begin{array}{l}\text { Cat } \\
(\mathrm{mg})\end{array}$ & $\begin{array}{c}\text { Al/Zr Molar } \\
\text { Ratio }\end{array}$ & $\begin{array}{l}\text { Yield } \\
\text { (g) }\end{array}$ & $\begin{array}{c}\text { Activity Kg } \\
\text { PE/mol Zr h bar }\end{array}$ & $\begin{array}{l}\text { Productivity } \\
\text { g PE/g cat h }\end{array}$ & $\begin{array}{c}\text { Bulk Density } \\
\text { g/mL }\end{array}$ \\
\hline S4 & 15.6 & 208 & 272 & 39.1 & 8033 & 376 & 0.30 \\
\hline S5 & 2.3 & 192 & 179 & 1.45 & 2189 & 15.1 & 0.11 \\
\hline $\mathrm{S} 12$ & 0.6 & 184 & 247 & - & - & - & - \\
\hline S14 & 16.7 & 211 & 254 & 37.8 & 7152 & 358 & 0.29 \\
\hline
\end{tabular}

*b Slurry polymerization condition: 3 bar ethylene pressure in $800 \mathrm{~mL}$ reactor of stainless steel, $350 \mathrm{~mL}$ hexane,

$80{ }^{\circ} \mathrm{C}, 2 \mathrm{~mL}$ (1 M in hexane) TIBA (scavenger), polymerization time: $30 \mathrm{~min}$.

From the polymerization results, we can see that the support plays a significant role on the supported metallocene catalyst and the polyolefin product. Therefore, the design and synthesis also is critical to the supported catalysts and the polyolefin product, especially on how to control the pore structure and the bulk density by choosing suitable functional comonomer(s) on the PDVB backbone.

\section{Conclusions}

A feasibility study on the design and synthesis of POP supports with a tunable pore structure and high performance of ethylene polymerization was conducted by the selection of functional comonomers, template agent, and control of the cross-linking degree of their frameworks. Functional porous organic polymers with a tunable pore structure and varied particle morphology were designed and synthesized, and the pore-size distributions of POPs are generally wider than the crystalline polymers, and the micropores and the mesopores could be tuned at the same time by the dispersion polymerization method. A single functional comonomer or dual comonomers in the PDVB-based POPs played a significant role in the porous structure and particle morphology of the prepared polymers, and different $\mathrm{N}_{2}$ isotherms and pore structure with SSA of $10-450 \mathrm{~m}^{2} / \mathrm{g}, \mathrm{PV}$ of $0.05-0.5 \mathrm{~cm}^{3} / \mathrm{g}$, and bulk density with a range of $0.02-0.40 \mathrm{~g} / \mathrm{cm}^{3}$ were obtained by the varied functional POPs, mainly due to their different functional groups and thermodynamic compatibility with the selected solvent system. Furthermore, the $\mathrm{Fe}_{3} \mathrm{O}_{4}$ nanoaggregates as a template agent could improve the porous structure and bulk density of the prepared POPs, and the highly cross-linking networks can dramatically increase the porous structure of the prepared POPs. The pore structure of the prepared POPs had a profound influence on the loading amount of the $\mathrm{Zr}$ and $\mathrm{Al}$ of the active sites, and the typically highly porous structure of the POPs would contribute the immobilization of the active species. High ethylene-polymerization activities of 8033 and $7152 \mathrm{~kg} \mathrm{PE} / \mathrm{mol} \mathrm{Zr} \mathrm{h}$ bar were 
achieved on the POPs-supported catalysts, especially when high $\mathrm{Al} / \mathrm{Zr}$ ratios on the catalysts were obtained. By replicating the effect, the produced PE obtained higher bulk densities from the POPs with higher bulk densities. Therefore, it is a facile and practical approach to tailor the active sites of the metallocene catalysts and polyolefin particle morphology through the design of pore structure and surface morphology of the prepared POPs.

Author Contributions: X.W. conceived and designed the experiments; X.W., C.Z., W.L., and P.Z. performed the experiments; X.W., C.Z., W.L., and P.Z. analyzed the data; X.W. wrote the paper.

Funding: This research received no external funding.

Acknowledgments: This work was financially supported by PetroChina Company Limited.

Conflicts of Interest: The authors declare no conflict of interest.

\section{References}

1. Yang, X.-Y.; Chen, L.-H.; Li, Y.; Rooke, J.C.; Sanchez, C.; Su, B.-L. Hierarchically porous materials: Synthesis strategies and structure design. Chem. Soc. Rev. 2017, 46, 481-558. [CrossRef] [PubMed]

2. Mondal, J.; Kundu, S.K.; Singuru, W.K.H.; Ng, R.; Borah, P.; Hirao, H.; Zhao, Y.; Bhaumik, A. Fabrication of ruthenium nanoparticles in porous organic polymers: Towards advanced heterogeneous catalytic nanoreactors. Chem. Eur. J. 2015, 21, 19016-19027. [CrossRef] [PubMed]

3. Sun, Q.; Dai, Z.; Meng, X.; Xiao, F.-S. Porous polymer catalysts with hierarchical structures. Chem. Soc. Rev. 2015, 44, 6018-6034. [CrossRef] [PubMed]

4. Fei, H.; Shin, J.; Meng, Y.S.; Adelhardt, M.; Sutter, J.; Meyer, K.; Cohen, S.M. Reusable oxidation catalysis using metal-monocatecholato species in a robust metal-organic framework. J. Am. Chem. Soc. 2014, 136, 4965-4973. [CrossRef] [PubMed]

5. Li, L.; Lin, R.-B.; Krishna, R.; Wang, X.; Lin, B.; Wu, H.; Li, J.; Zhou, W.; Chen, B. Flexible-robust metal-organic framework for efficient removal of propyne from propylene. J. Am. Chem. Soc. 2017, 139, 7733-7736. [CrossRef] [PubMed]

6. Dawson, R.; Cooper, A.I.; Adams, D.J. Nanoporous organic polymer networks. Prog. Polym. Sci. 2012, 37, 530-563. [CrossRef]

7. Bildirir, H.; Osken, I.; Ozturk, T.; Thomas, A. Reversible doping of a dithienothiophene-based conjugated microporous polymer. Chem. Eur. J. 2015, 21, 9306-9311. [CrossRef] [PubMed]

8. Gomes, R.; Bhaumik, A. Highly porous organic polymers bearing tertiary amine group and their exceptionally high $\mathrm{CO}_{2}$ uptake capacities. J. Solid State Chem. 2015, 222, 7-11. [CrossRef]

9. Furukawa, H.; Ko, N.; Go, Y.B.; Aratani, N.; Choi, S.B.; Choi, E.; Yazaydin, A.O.; Snurr, R.Q.; O'Keeffe, M.; $\mathrm{Kim}, \mathrm{J}$; et al. Ultrahigh porosity in metal-organic frameworks. Science 2010, 329, 424-428. [CrossRef] [PubMed]

10. Kim, M.J.; Ahn, S.; Yi, J.; Hupp, J.T.; Notestein, J.M.; Farha, O.K.; Lee, S.J. Ni(II) complex on a bispyridine-based porous organic polymer as a heterogeneous catalyst for ethylene oligomerization. Catal. Sci. Technol. 2017, 7, 4351-4354. [CrossRef]

11. Ji, P.; Solomon, J.B.; Lin, Z.; Johnson, A.; Jordan, R.F.; Lin, W. Transformation of metal-organic framework secondary building units into hexanuclear Zr-alkyl catalysts for ethylene polymerization. J. Am. Chem. Soc. 2017, 139, 11325-11328. [CrossRef] [PubMed]

12. Wang, X.; Xu, R.; Zhu, B.; Li, Y.; Han, X. Metal oxide as a template in the preparation of porous poly(2-hydroxyethylmethylacrylate-co-divinylbenzene) particles as a metallocene catalyst support. RSC Adv. 2016, 6, 52464-52474. [CrossRef]

13. Damiani, D.E.; Ferreia, M.L.; Santos, J.H.Z.; Belelli, P.G.; Vayá, V.I. Influence of acidic support in metallocene catalysts for ethylene polymerization. J. Catal. 2001, 204,1-10.

14. Severn, J.R.; Chadwick, J.C.; Duchateau, R.; Friederichs, N. "Bound but not gagged"-Immobilizing single-site $\alpha$-olefin polymerization catalysts. Chem. Rev. 2005, 105, 4073-4147. [CrossRef] [PubMed]

15. Shen, J.; Xu, K.; Feng, L.; Wang, L.; Yuan, Y. A novel zirconocene/ultradispersed diamond black powder supported catalytic system for ethylene polymerization. Eur. Polym. J. 2002, 38, 2125-2128. 
16. Sacchi, M.C.; Zucchi, D.; Tritto, I.; Locatelli, P. Silica-supported metallocenes: Stereochemical comparison between homogeneous and heterogeneous catalysis. Macromol. Rapid Commun. 1995, 16, 581-590. [CrossRef]

17. Roscoe, S.B.; Fréchet, J.M.; Walzer, J.F.; Dias, A.J. Polyolefin spheres from metallocenes supported on noninteracting polystyrene. Science 1998, 280, 270-273. [CrossRef] [PubMed]

18. Nishida, H.; Uozumi, T.; Arai, T.; Soga, K. Polystyrene-supported metallocene catalysts for olefin polymerizations. Macromol. Rapid Commun. 1995, 16, 821-830. [CrossRef]

19. Hong, S.C.; Teranishi, T.; Soga, K. Investigation on the polymer particle growth in ethylene polymerization with PS beads supported rac- $\mathrm{Ph}_{2} \mathrm{Si}(\mathrm{Ind})_{2} \mathrm{ZrCl}_{2}$ catalyst. Polymer 1998, 39, 7153-7157. [CrossRef]

20. Kaur, P.; Hupp, J.T.; Nguyen, S.T. Porous organic polymers in catalysis: Opportunities and challenges. ACS Catal. 2011, 1, 819-835. [CrossRef]

21. Lin, Z.; Lu, J.; Li, L.; Li, H.-F.; Cao, R. Defect porous organic frameworks (dPOFs) as a platform for chiral organocatalysis. J. Catal. 2017, 355, 131-138. [CrossRef]

22. Zhang, Y.; Riduan, S.N. Functional porous organic polymers for heterogeneous catalysis. Chem. Soc. Rev. 2012, 41, 2083-2094. [CrossRef] [PubMed]

23. Lin, S.; Diercks, C.S.; Zhang, Y.-B.; Kornienko, N.; Nichols, E.M.; Zhao, Y.; Paris, A.R.; Kim, D.; Yang, P.; Yaghi, O.M.; et al. Covalent organic frameworks comprising cobalt porphyrins for catalytic $\mathrm{CO}_{2}$ reduction in water. Science 2015, 349, 1208-1213. [CrossRef] [PubMed]

24. Liu, Y.; Ma, Y.; Zhao, Y.; Sun, X.; Gandara, F.; Furukawa, H.; Liu, Z.; Zhu, H.; Zhu, C.; Suenaga, K.; et al. Weaving of organic threads into a crystalline covalent organic framework. Science 2016, 351, 365-369. [CrossRef] [PubMed]

25. Rozhko, E.; Bavykina, A.; Osadchii, D.; Makkee, M.; Gascon, J. Covalent organic frameworks as supports for a molecular Ni based ethylene oligomerization catalyst for the synthesis of long chain olefins. J. Catal. 2017, 345, 270-280. [CrossRef]

26. Zou, X.; Ren, H.; Zhu, G. Topology-directed design of porous organic frameworks and their advanced applications. Chem. Commun. 2013, 49, 3925-3936. [CrossRef] [PubMed]

27. Waller, P.J.; Gandara, F.; Yaghi, O.M. Chemistry of covalent organic frameworks. Acc. Chem. Res. 2015, 45, 3053-3063. [CrossRef] [PubMed]

28. Huang, N.; Krishna, R.; Jiang, D. Tailor-made pore surface engineering in covalent organic frameworks: Systematic functionalization for performance screening. J. Am. Chem. Soc. 2015, 137, 7079-7082. [CrossRef] [PubMed]

29. Klet, R.C.; Tussupbayev, S.; Borycz, J.; Gallagher, J.R.; Stalzer, M.M.; Miller, J.T.; Gagliardi, L.; Hupp, J.T.; Marks, T.J.; Cramer, C.J.; et al. Single-site organozirconium catalyst embedded in a metal-organic framework. J. Am. Chem. Soc. 2015, 137, 15680-15683. [CrossRef] [PubMed]

30. Comito, R.J.; Wu, Z.; Zhang, G.; Lawrence, J.A., III; Korzynski, M.D.; Kehl, J.A.; Miller, J.T.; Dinca, M. Stabilized vanadium catalyst for olefin polymerization by site isolation in a metal-organic framework. Angew. Chem. Int. Ed. 2018, 57, 8135-8139. [CrossRef] [PubMed]

31. Taddei, M. When defects turn into virtues: The curious case of zirconium-based metal-organic frameworks. Coord. Chem. Rev. 2017, 343, 1-24. [CrossRef]

32. Budd, P.M.; Ghanem, B.S.; Makhseed, S.; McKeown, N.B.; Msayib, K.J.; Tattershall, C.E. Polymers of intrinsic microporosity (PIMs): Robust, solution-processable, organic nanoporous materials. Chem. Commun. 2004, 4, 230-231. [CrossRef] [PubMed]

33. Jiang, J.-X.; Su, F.; Trewin, A.; Wood, C.D.; Campbell, N.L.; Niu, H.; Dickinson, C.; Ganin, A.Y.; Rosseinsky, M.J.; Khimyak, Y.Z.; et al. Conjugated microporous poly(aryleneethynylene) networks. Angew. Chem. Int. Ed. 2007, 46, 8574-8578. [CrossRef] [PubMed]

34. Thomas, A. Functional materials: From hard to soft porous frameworks. Angew. Chem. Int. Ed. 2010, 49, 8328-8344. [CrossRef] [PubMed]

35. Wang, X.; Xu, R.; Zhu, B.; Li, Y.; Ma, Y. Synthesis and characterization of functional porous organic polymers as efficient metallocene catalyst supports. New J. Chem. 2016, 40, 8324-8333. [CrossRef]

36. Wang, X.; Li, Z.; Han, X.; Han, Z.; Bai, Y. Highly tunable porous organic polymer (POP) supports for metallocene-based ethylene polymerization. Appl. Surf. Sci. 2017, 420, 496-503. [CrossRef]

37. Wang, X.; Han, X.; Ren, F.; Xu, R.; Bai, Y. Porous organic polymers-supported metallocene catalysts for ethylene/1-hexene copolymerization. Catalysts 2018, 8, 146. [CrossRef] 
38. Paine, A.J. Dispersion polymerization of styrene in polar solvents. 7. A simple mechanistic model to predict particle size. Macromolecules 1990, 23, 3109-3117. [CrossRef]

39. Liu, Q.; Wang, L.; Xiao, A.; Yu, H.; Tan, Q.; Ding, J.; Ren, G. Unexpected behavior of 1-chlorodecane as a novel porogen in the preparation of high-porosity poly(divinylbenzene) microspheres. J. Phys. Chem. C 2008, 112, 13171-13174. [CrossRef]

40. Bonini, F.; Fraajie, V.; Fink, G. Propylene polymerization through supported metallocene/MAO catalysts: Kinetic analysis and modeling. J. Polym. Sci. Part A 1995, 33, 2393-2402. [CrossRef]

41. Fink, G.; Steinmetz, B.; Zechlin, J.; Przybyla, C.; Tesche, B. Propene polymerization with silica-supported metallocene/MAO catalysts. Chem. Rev. 2000, 100, 1377-1390. [CrossRef] [PubMed]

2018 by the authors. Licensee MDPI, Basel, Switzerland. This article is an open access article distributed under the terms and conditions of the Creative Commons Attribution (CC BY) license (http://creativecommons.org/licenses/by/4.0/). 